\title{
The Activity of [60]Fullerene Derivatives Bearing Amine and Carboxylic Solubilizing Groups against Escherichia coli: A Comparative Study
}

\author{
Dmitry G. Deryabin, ${ }^{1,2}$ Olga K. Davydova, ${ }^{1}$ Zulfiya ZH. Yankina, ${ }^{1}$ \\ Alexey S. Vasilchenko, ${ }^{1,3}$ Sergei A. Miroshnikov, ${ }^{2}$ Alexey B. Kornev, ${ }^{4}$ \\ Anastasiya V. Ivanchikhina, ${ }^{4}$ and Pavel A. Troshin ${ }^{4}$ \\ ${ }^{1}$ Department of Microbiology, Orenburg State University, Pobedy Avenue 13, Orenburg 460018, Russia \\ ${ }^{2}$ All-Russia Research Institute of Beef Cattle Breeding, 9 Yanvarya Street 29, Orenburg 460000, Russia \\ ${ }^{3}$ Institute of Cellular and Intracellular Symbiosis, RAS, Pionerskaya Street 11, Orenburg 460000, Russia \\ ${ }^{4}$ Institute for Problems of Chemical Physics of RAS, Academician Semenov Avenue 1, Chernogolovka, Moscow Region 142432, Russia
}

Correspondence should be addressed to Dmitry G. Deryabin; dgderyabin@yandex.ru

Received 5 September 2013; Accepted 13 November 2013; Published 15 January 2014

Academic Editor: Myoung-Woon Moon

Copyright (C) 2014 Dmitry G. Deryabin et al. This is an open access article distributed under the Creative Commons Attribution License, which permits unrestricted use, distribution, and reproduction in any medium, provided the original work is properly cited.

\begin{abstract}
We report a comparative investigation of the antibacterial activity of two water-soluble fullerene derivatives bearing protonated amine (AF) and deprotonated carboxylic (CF) groups appended to the fullerene cage via organic linkers. The negatively charged fullerene derivative CF showed no tendency to bind to the bacterial cells and, consequently, no significant antibacterial activity. In contrast, the compound AF loaded with cationic groups showed strong and partially irreversible binding to the negatively charged Escherichia coli K12 TG1 cells and to human erythrocytes, also possessing negative zeta potential. Adsorption of AF on the bacterial surface was visualized by atomic force microscopy revealing the formation of specific clusters (AF aggregates) surrounding the bacterial cell. Incubation of $E$. coli $\mathrm{K} 12 \mathrm{TG1}$ with AF led to a dose-dependent bactericidal effect with $\mathrm{LD}_{50}=79.1 \mu \mathrm{M}$. The presence of human erythrocytes in the test medium decreased the AF antibacterial activity. Thus we reveal that the water-soluble cationic fullerene derivative AF possesses promising antibacterial activity, which might be utilized in the development of novel types of chemical disinfectants.
\end{abstract}

\section{Introduction}

Investigation of carbon-based nanomaterials (CBN) has made a great impact on the research in the fields of physics, material chemistry and technology, and also life sciences. Water-soluble forms of carbon have been studied intensively worldwide during recent decades. We would like to refer to [1], dedicated to the studies of biological activity of CBN [1]. Toxicity and biocompatibility of CBN were two major points addressed in this journal. Several review papers discussing the biological activities of CBN appeared later [2-4].

Fullerenes, the spherical carbon cages, and their functional derivatives attracted particular attention due to their unusual molecular structures and properties. Recent publications proved lower toxicity of fullerenes compared to other types of CBN, especially carbon nanotubes $[5,6]$. It is known that pristine fullerenes such as $\mathrm{C}_{60}$ and $\mathrm{C}_{70}$ are very hydrophobic and possess virtually zero solubility in water. Classical fullerene derivatives bearing one organic addend appended to the fullerene cage typically have a strong tendency to aggregate in aqueous solutions [7]. Such aggregation lowers their activity significantly and hinders their practical applications. The problem can be solved by using chemically functionalized fullerene derivatives bearing a sufficient number of hydrophilic (or, even better, ionic) functional groups that significantly improve the solubility of these compounds in water $[8,9]$.

A number of studies have reported effective gene delivery [10] and antioxidative [11], neuroprotective [12], antitumour 
[13], and antiviral [14] activities of fullerenes and their derivatives, which makes further exploration of this exciting family of CBN promising. Interesting results were obtained while studying antimicrobial activity of fullerenes [15]. It was proposed that membrane targeting [16], respiratory chain inhibition [17], and photosensitizing effects [18] of fullerene derivatives are responsible for the observed antibacterial action. Functionalizing the carbon cage with hydrophilic functional groups brings up new biological properties. For example, alkylated $\mathrm{C}_{60}$-bis $(\mathrm{N}, \mathrm{N}$-dimethylpyrrolidinium iodide) adducts inhibited bacterial growth effectively [19]. Similarly, a carboxylic derivative of [60]fullerene bearing malonic acid fragments on the carbon cage protected mice from bacteria-induced meningitis without direct bacterial inhibition [20]. It should be emphasized that mechanisms of the observed antibacterial activity and selectivity of different types of fullerene derivatives are not currently well understood.

Recently we have succeeded in the selective synthesis of different types of water-soluble fullerene derivatives possessing 4-8 organic addends attached to the cages of $\mathrm{C}_{60}$ and $\mathrm{C}_{70}$ fullerenes [21-24]. These compounds became available on a large (multigram) scale sufficient for performing a thorough investigation of their biological activities $[25,26]$. In the present work, we performed a comparative study of antibacterial activity of two different water-soluble derivatives of [60]fullerene bearing protonated amine (AF) and carboxylate $(\mathrm{CF})$ groups appended to the fullerene cage via organic linkers (Figure 1).

\section{Experimental}

2.1. Fullerene Derivatives. The fullerene derivatives AF, bearing four protonated 4-(2-pyridyl)piperazine-1-yl groups, and $\mathrm{CF}$, comprising five residues of phenylacetic acid, were synthesized according to the previously published procedures $[25,26]$. Spectroscopic characteristics of the prepared samples were identical to the previously reported data $[25,26]$.

\subsection{Preparation and Characterization of Aqueous Fullerene} Suspensions. Aqueous suspensions of fullerene derivatives $(4 \mathrm{mg} / \mathrm{mL})$ were prepared in deionized water, filtered through syringe filters, and poured into vials that were prewashed several times with filtered water in order to remove dust particles. The suspensions were then incubated for about 2 hours at $20^{\circ} \mathrm{C}$, thus allowing the colloidal systems to reach an equilibrium. The temperature control accuracy was $0.1^{\circ} \mathrm{C}$.

The size of fullerene aggregates in aqueous suspension was measured using dynamic light scattering (DLS) with a Photocor Complex (Photocor Instruments Inc., USA) setup equipped with a He-Ne laser $(\lambda=679.5 \mathrm{~nm})$. The mutual diffusion coefficients of fullerene aggregates were computed from the DLS data using the DynaLS program (Alango, Israel). Hydrodynamic diameters of the fullerene aggregates were calculated from the mutual diffusion coefficients using the Einstein-Stokes formula for diffusion coefficients of spherical particles.
Electrophoresis of fullerene derivatives was performed in a $1.5 \%$ agarose gel at a constant voltage of $150 \mathrm{~V}$ and current of $100 \mathrm{~mA}$, so that the electric field strength was $5 \mathrm{~V} / \mathrm{cm}$. After $20 \mathrm{~min}$ of electrophoresis, migration of compounds was evaluated by visible and UV light on a transilluminator (Vilber Lourmat, France). The Smoluchowski equation was used to calculate the $\zeta$-potential from the electrophoretic mobility.

Adsorption and fluorescence spectra of fullerene derivatives in aqueous suspensions were recorded with a Fluorat-02 Panorama spectrofluorometer (Lumex, Russia) in a spectral range of $220-400 \mathrm{~nm}$.

2.3. Bacterial Strain and Cultures Preparation. The experiments involving bacterial cells were performed using the Escherichia coli K12 TG1 strain. The applicability of this strain for evaluation of bactericidal activity of a wide range of carbon-based nanomaterials has been demonstrated previously [26]. The bacteria were grown in LB-broth (SigmaAldrich, USA) for $18-24$ hours at $37^{\circ} \mathrm{C}$, after which the cells were harvested by centrifugation at $1000 \mathrm{~g}$ for $10 \mathrm{~min}$, washed once with the distilled water, and diluted to achieve the optical density of 0.5 absorption units at $640 \mathrm{~nm}$, which corresponds to the concentration of $3.5 \times 10^{9}$ colony-forming units (CFU) per $1 \mathrm{~mL}$.

The human erythrocytes were collected from blood (0 $\mathrm{Rh}+$ ) by centrifugation at $1000 \mathrm{~g}$ for $10 \mathrm{~min}$ and washing the precipitate with $0.85 \% \mathrm{NaCl}$ solution twice. The final concentration of erythrocytes was $7 \times 10^{8}$ cells $/ \mathrm{mL}$, which is equal to the surface area of $0.02 \mathrm{~m}^{2} / \mathrm{mL}$.

2.4. Investigation of Adsorption/Desorption of Fullerene Derivatives on the Cell Surfaces. Fullerene derivatives AF and $\mathrm{CF}$ were introduced to the cell suspensions to prepare a series of samples with $2,1,0.5,0.25,0.12,0.06$, and $0.03 \mu \mathrm{M}$ concentrations of the compounds. After incubation at $37^{\circ} \mathrm{C}$ for 60 minutes, the prokaryotic and eukaryotic cells modified with the fullerene derivatives were separated by centrifugation at $1000 \mathrm{~g}$ for $10 \mathrm{~min}$. The concentration of unbound fullerene derivative in the supernatant was determined using fluorimetry in the case of $\mathrm{AF}$ and photometry in the case of $\mathrm{CF}$. The value of the adsorption was calculated using

$$
A=\frac{\left(C_{0}-C_{e}\right)}{S},
$$

where $C_{0}$ is the starting concentration of the fullerene derivative, $C_{e}$ is the equilibrium concentration of the fullerene derivative after partial adsorption to the cell membranes (determined in supernatant), and $S$ is the surface area of the cells.

The evaluation of the fullerene derivative desorption from the bacterial cells surfaces was performed by dispersing the E. coli $\mathrm{K} 12 \mathrm{TG1}$ cells in the solutions of $\mathrm{AF}\left(C_{0}=1 \mu \mathrm{M}\right)$ and $\mathrm{CF}\left(C_{0}=10 \mu \mathrm{M}\right)$; is incubation of these dispersions for $60 \mathrm{~min}$ is followed by centrifugation. The precipitated bacterial biomass was separated and dispersed again in an equal volume of distilled water, while the supernatant liquor 


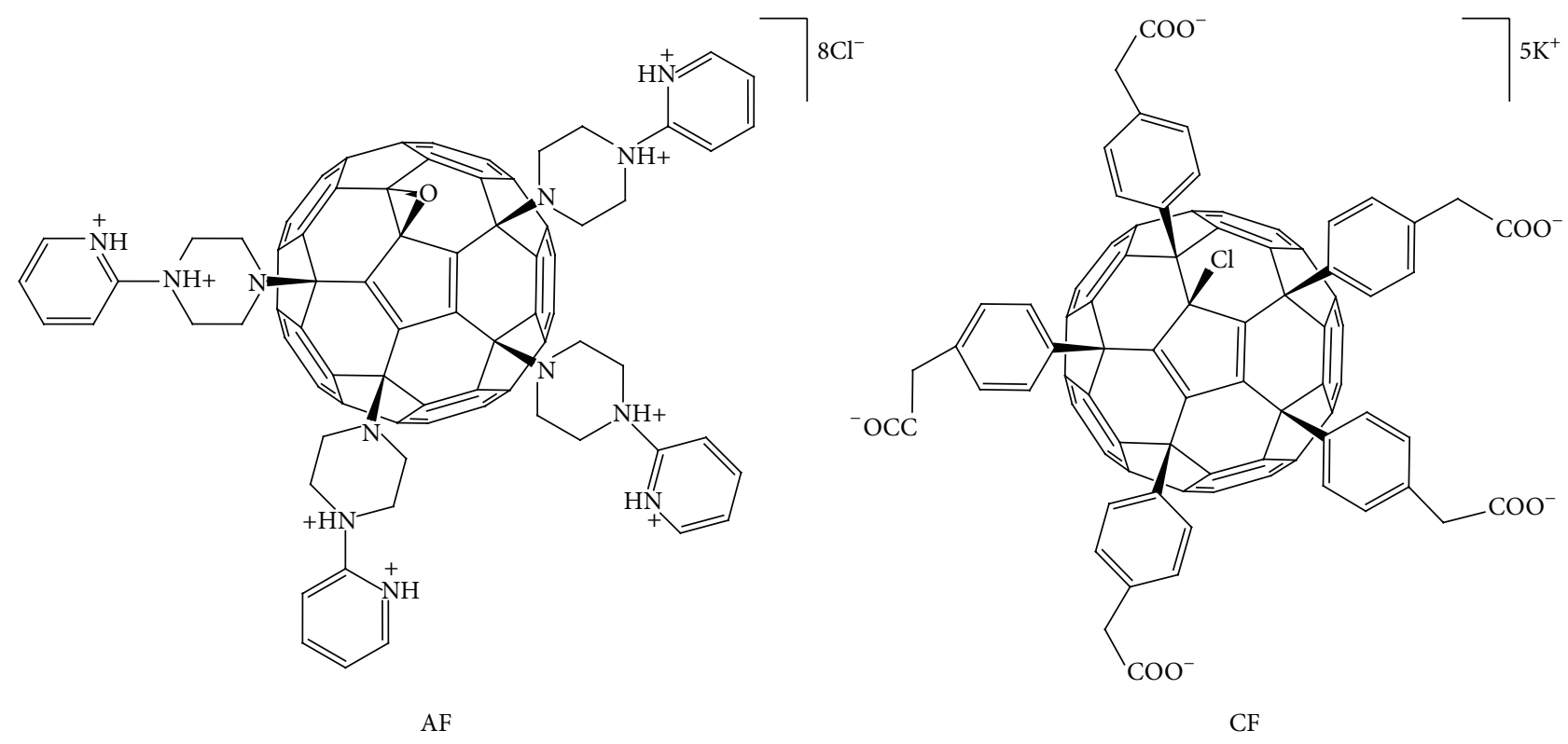

Figure 1: Molecular structures of the fullerene derivatives AF and CF.

was analysed using fluorimetry or photometry to reveal the concentrations of the $\mathrm{AF}$ and $\mathrm{CF}$, respectively. The bacterial cells that were redispersed in distilled water were subjected again to centrifugation and the concentration of the fullerene derivative in the supernatant liquid was determined. Washing the bacterial biomass with distilled water was repeated ten times and each time the fullerene derivative concentration in the supernatant was determined in order to reconstruct the desorption profiles.

2.5. Atomic Force Microscopy. Visualization of the bacterial cells in the intact form or after incubation with the fullerene derivatives was performed using an atomic force microscope (SMM-2000; Proton-MIET, Russia). An aliquot $(20 \mu \mathrm{L})$ of the suspension comprising either intact cells of $E$. coli $\mathrm{K} 12$ TG1 or their mixtures with AF and CF was applied to the freshly prepared mica at $95 \%$ relative humidity and $20-22^{\circ} \mathrm{C}$. The samples were scanned in a contact mode using V-shaped silicon nitride cantilevers MSCT-AUNM (Veeco Instruments Inc., USA) with a spring constant of $0.01 \mathrm{~N} / \mathrm{m}$ and a tip curvature of 150-250 Á. Quantitative morphometrical analysis of the images was performed using standard software provided with the microscope.

2.6. Bactericidal Activity of Fullerene Derivatives. The test samples comprised a suspension of $E$. coli $\mathrm{K} 12 \mathrm{TG1}$ at a concentration of $3.5 \times 10^{9} \mathrm{CFU} / \mathrm{mL}$ and the fullerene derivatives were added in concentrations ranging from 25 to $200 \mu \mathrm{M}$. In a separate series of experiments, $E$. coli was incubated with fullerene derivatives in the presence of human erythrocytes at a concentration $7 \times 10^{8}$ cells $/ \mathrm{mL}$. This concentration of erythrocytes provided an equal surface area compared to the total area of the bacterial cell membranes $\left(0.02 \mathrm{~m}^{2} / \mathrm{mL}\right)$. Lysis of erythrocytes was induced by addition of $0.05 \%$ saponin prior to plating the prepared cultures in the BCPagar medium.

The $100 \mu \mathrm{L}$ aliquots taken from the experimental samples $60 \mathrm{~min}$ after the fullerene derivative addition and the control samples comprising no fullerene derivatives were diluted with $900 \mu \mathrm{L}$ of distilled water. Small portions of the obtained test samples $(10 \mu \mathrm{L})$ were inoculated on the plates with BCP-agar (Bio-Merieux, France). The percentage of the bacterial cells retaining their viability during incubation with fullerenes (calculated as the total number of CFU in an experimental sample divided by the number of CFU in the control series) was determined after an additional $18-24 \mathrm{~h}$ incubation of the samples at $37^{\circ} \mathrm{C}$. The dose of the fullerene derivative causing the death of $50 \%$ of the microbial cells $\left(\mathrm{LD}_{50}\right)$ was obtained from these experiments.

\section{Results and Discussion}

3.1. Characterization of Aqueous Fullerene Suspensions. The attachment of the cationic (protonated amine, AF) or anionic (COO-, CF) functional groups to the [60]fullerene cage significantly increased the solubility of the fullerene derivatives in water. The resulting aqueous solutions of $\mathrm{AF}$ and CF (concentration $4 \mathrm{mg} / \mathrm{mL}$ ) were transparent and had a bright orange-brown colour. No fullerene precipitation was observed in the course of the experiments indicating that the prepared aqueous systems were rather stable with respect to aggregation and sedimentation of the dissolved/dispersed compounds.

The dynamic light scattering (DLS) experiments allowed the determination of the hydrodynamic sizes of the fullerene nanoparticles in aqueous suspensions. The DLS experiments showed that both [60] fullerene derivatives form aggregates in aqueous solutions with diameters of 2-200 nm (AF) and 70$100 \mathrm{~nm}(\mathrm{CF})$ (Figure 2). Larger particles of $10^{4}-10^{6} \mathrm{~nm}(\mathrm{AF})$ 


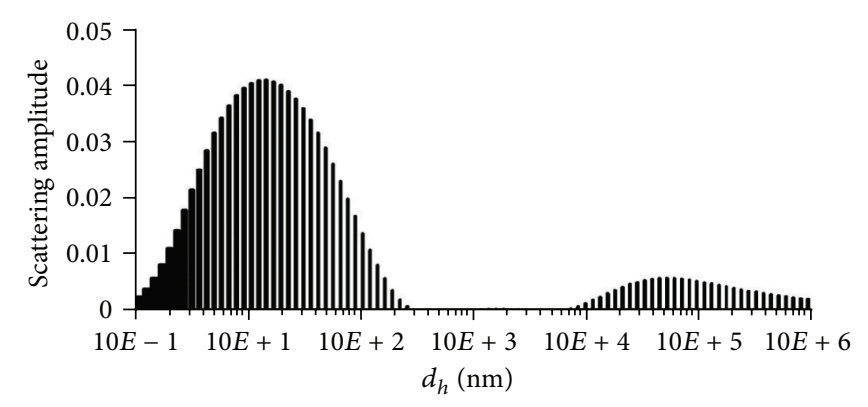

(a)

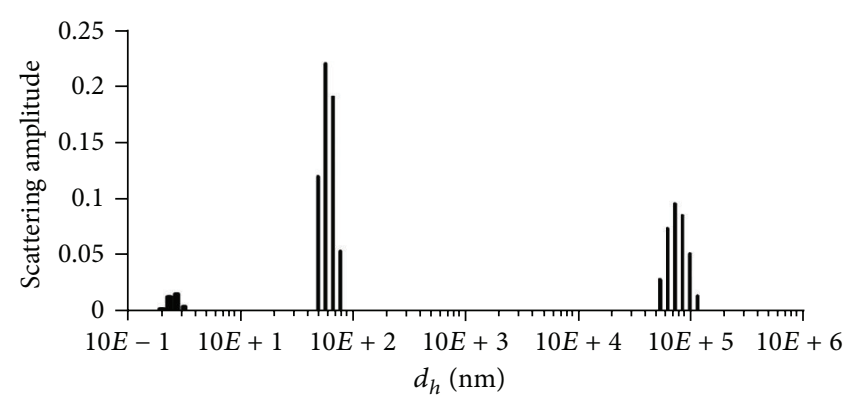

(b)

FigURE 2: DLS profiles for aqueous suspensions of AF (a) and CF (b) fullerene derivatives.

and $\sim 10^{5} \mathrm{~nm}$ (CF) correspond, most likely, to some larger aggregates composed of the fullerene derivative aggregates.

The DLS measurements indicated that the fullerene aggregates formed in aqueous systems have rather high polydispersity, particularly in the case of AF. These data correspond well to the previous reports describing spherical and irregularly shaped fullerene-based nanoparticles as revealed by DLS, TEM, and high-resolution TEM [26-30]. Very similar nanoclusters were also observed in this work using atomic force microscopy (AFM) (see Section 3.4); therefore, DLS and AFM measurements showed that fullerene derivatives AF and CF undergo aggregation in aqueous solutions. Taking into account the typical size of these aggregates, the bicomponent systems comprising the fullerene derivative and water should be called a colloidal solution or even suspension rather than a true solution.

3.2. Detection of Electric Charge and Zeta Potentials of Fullerene Derivatives. The agarose gel electrophoresis performed for the water-soluble fullerene derivatives AF and CF showed that they represent highly charged cationic and anionic species (Table 1). Motion of the carboxylic fullerene derivative towards the anode was clearly detectable with the naked eye. Movement of the amino fullerene towards the cathode was visualized with a UV transilluminator owing to the reasonably strong fluorescence of the AF compound (see Section 3.3).

The calculated zeta potentials $(\zeta)$ of AF and CF were $+41.5 \mathrm{mV}$ and $-52.2 \mathrm{mV}$, respectively. It is known that aqueous fullerene suspensions are stable if the zeta potentials of the dispersed particles are smaller than $-15 \mathrm{mV}$ or higher than $+15 \mathrm{mV}$ [31]. Very pronounced cationic and anionic properties of AF and CF, respectively, reflected in the values of their zeta potentials, explain the high solubility of these compounds in water. It should also be noted that compounds of AF and CF have rather large dipole moments since organic addends bearing ionic groups are located at one hemisphere of the fullerene cage.

Moreover, the functionalized part of the fullerene cage becomes hydrophilic, while the opposite side of the carbon sphere remains hydrophobic. Therefore, peculiarities of the molecular structures of AF and CF enable electrostatic dipole-dipole and hydrophobic-hydrophilic interactions. Thus, van der Waals attraction forces [32] bring the molecules of the fullerene derivatives together forming suspensions of solvated nanoparticles rather than true molecular solutions.

3.3. Spectroscopic Study of Fullerene Derivatives. An aqueous suspension of CF exhibits one distinct adsorption band with the maximum at $230 \mathrm{~nm}$, while the AF suspension shows two bands with maxima at 240 and $300 \mathrm{~nm}$ (Figure 3(a)).

It is surprising that the amino fullerene showed unusually strong fluorescence with maxima at $360 \mathrm{~nm}$ under excitation with ultraviolet light at 240 or $300 \mathrm{~nm}$. An excitation of AF solution at $240 \mathrm{~nm}$ produced 1.8 times higher fluorescence intensity compared to the excitation at $300 \mathrm{~nm}$. The fluorescence intensity linearly depended on the concentration of AF in the range of $0-2 \mu \mathrm{M}$ (Figure $3(\mathrm{~b})$ ).

The fluorescence was observed previously for pristine [60]fullerene and its derivatives. Compared to the week fluorescence of pristine C60 $\left(\lambda_{\max }=689 \mathrm{~nm}\right)$ [33], the functionalized fullerenes show stronger emission bands shifted to the short-wave spectral range. For instance, blue-shifted fluorescence was reported for the fullerene derivatives bearing eight or ten pyridyl groups attached to the carbon cage [34].

In this study we used the fluorescence spectroscopy to perform an accurate investigation of AF adsorption and desorption on the surface of prokaryotic or eukaryotic cells. In the case of the nonfluorescent $\mathrm{CF}$ derivative, a photometric method was used for determination of its concentration in the experimental solutions.

3.4. Adsorption of the Fullerene Derivatives on the Surface of Prokaryotic or Eukaryotic Cells. The prokaryotic (E. coli) or eukaryotic (human erythrocyte) cells were incubated with the suspensions of the fullerene derivative AF at concentrations ranging from 0.03 to $1 \mu \mathrm{M}$. Then the cells loaded with the fullerene derivative were separated by centrifugation and the supernatant liquid was subjected to fluorescence analysis.

The fluorescence measurements revealed the residual amount of amino fullerene that was not adsorbed by the cells. These experiments show that AF has similarly strong but not identical affinity to both types of cell surfaces. An increase in the AF concentration resulted in a stronger binding of this compound to the cell membranes reflected by higher binding indexes (Table 2). 
TABLE 1: Fullerene derivatives electrophoretic mobility and zeta-potentials.

Compound
Mobility in the electric field
(the cathode side is on the left; the anode side is on the right)

TABLE 2: AF adsorption values on E. coli K12 TG1 cells and human erythrocytes.

\begin{tabular}{lcccc}
\hline \multicolumn{3}{c}{$\begin{array}{c}\text { Concentration of } \mathrm{AF}, \mu \mathrm{M} \\
\text { Initial }\end{array}$} & \multicolumn{2}{c}{ Adsorption values, $\mu \mathrm{M} / \mathrm{m}^{2}$} \\
& E. coli & Erythrocytes & E. coli & Erythrocytes \\
\hline 0.03 & $0.03 \pm 0.01$ & $0.02 \pm 0.01$ & 1.50 & 1.00 \\
0.06 & $0.06 \pm 0.01$ & $0.06 \pm 0.01$ & 3.00 & 3.00 \\
0.12 & $0.11 \pm 0.02$ & $0.10 \pm 0.02$ & 5.50 & 5.00 \\
0.25 & $0.18 \pm 0.01$ & $0.16 \pm 0.01$ & 9.00 & 8.00 \\
0.50 & $0.40 \pm 0.02$ & $0.23 \pm 0.03$ & 20.00 & 11.50 \\
1.00 & $0.54 \pm 0.17$ & $0.39 \pm 0.11$ & 27.00 & 19.50 \\
\hline
\end{tabular}

It is seen from Table 2 that AF when used in high concentrations has somewhat stronger affinity to the E. coli cells compared to the human erythrocytes. For example, the maximal adsorption values of $27.0 \mu \mathrm{M} / \mathrm{m}^{2}$ and $19.5 \mu \mathrm{M} / \mathrm{m}^{2}$ were obtained for $E$. coli and erythrocytes, respectively, when $\mathrm{AF}$ was added at an initial concentration of $1 \mu \mathrm{M}$.

Similar experiments were also performed for CF incubated with prokaryotic and eukaryotic cells. Due to the lower affinity of CF to the cell membranes, its initial concentration was increased to $10 \mu \mathrm{M}$. However, the fullerene derivative CF showed very weak adsorption on bacterial and erythrocyte cell surfaces, as characterized by maximal adsorption values of $1.91 \mu \mathrm{M} / \mathrm{m}^{2}$ and $2.64 \mu \mathrm{M} / \mathrm{m}^{2}$, respectively.

The binding of AF to the bacterial cells was confirmed by atomic force microscopy. Contact mode AFM allowed us to visualize the cells of $E$. coli before (Figure 4(a)) and after (Figure 4(b)) incubation with AF.

The analysis of the morphological characteristics of the bacterial cell incubated with AF showed a significant increase in the surface roughness. This change was caused by the granules $(35-160 \mathrm{~nm}$ in diameter) that accumulated on the cell surface. We believe that these granules are represented by nanoclusters composed of AF molecules, which were also revealed by the DLS measurements (see above). In addition, the $E$. coli cells changed their length, width, and height, thus supporting additionally the action of the AF derivative. It is important to note that no signs of leakage of the cytosolic content of the bacterial cells to the environment were observed. This observation implies that the membrane disruption is not the leading mechanism of antibacterial activity of fullerenes $[35,36]$ in contrast to the action of other types of CBN [37].

Analysis of the morphological characteristics of $E$. coli cells incubated with CF did not reveal any significant changes in the cell surface roughness or size (Figure 4(c)). At the same time, scanning the substrate (mica) around the bacterial cells revealed freely located round-shaped features with a mean diameter of $217.90 \pm 89.71 \mathrm{~nm}$. These features might be attributed to the aggregates of the CF molecules also evident from the DLS data.

The sharply different behaviour of AF and CF with respect to the prokaryotic (bacterial) and eukaryotic (erythrocyte) cells can be explained mainly by the electrostatic forces. Indeed, the cationic $\mathrm{AF}(\zeta=+41.5 \mathrm{mV})$ should have strong Coulomb attraction to the negatively charged $E$. coli cells $(\zeta=-50.0 \mathrm{mV})[38]$ and somewhat weaker attraction to the less negatively charged human erythrocytes $(\zeta=-13.5 \mathrm{mV})$ [39]. At the same time, the anionic fullerene derivative CF bearing a negative charge itself $(\zeta=-52.2 \mathrm{mV})$ cannot interact effectively with the surface of the prokaryotic and eukaryotic cells due to the Coulomb repulsion. The proposed mechanism relying on electrostatic interactions between the fullerene derivatives (or their aggregates) and cell membranes can explain both antibacterial [40] and cytotoxic [41, 42] effects of the fullerene derivatives. However, one should keep in mind that electrostatic interactions could be just an initial step of a complicated cascade of processes that occur when prokaryotic or eukaryotic cells are incubated with the fullerene derivatives.

3.5. Desorption of Fullerene Derivatives from the E. coli Cell Surface. In order to check the strength and reversibility of the AF and CF binding to the bacterial cell surface, we analysed the desorption of these compounds using a very simple experiment (see Section 2). The obtained AF and CF desorption values are shown in Table 3.

It was shown that the binding of the amino fullerene AF to the bacterial cells is strong and partially irreversible. It is seen from Table 3 that only $64.7 \pm 1.6 \%$ of initially adsorbed AF was desorbed from the bacterial cells after 10 washing cycles. Moreover, excretion of fullerene occurs gradually and the last cycles showed very little and decreasing desorption of AF, 


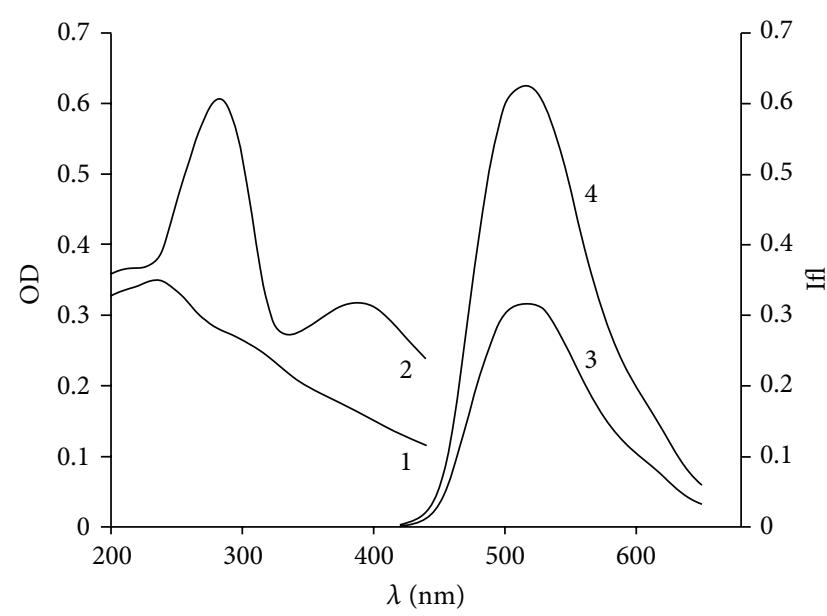

(a)

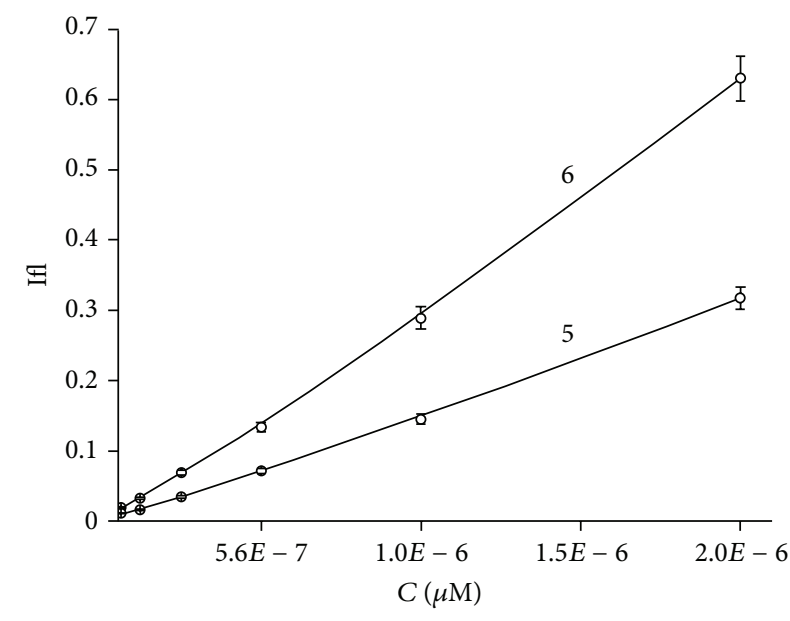

(b)

Figure 3: Optical spectra of the fullerene derivatives. (a) Adsorption spectra of CF, $C=2 * 10^{-6} \mathrm{M}(1)$, and AF, $C=2 * 10^{-5} \mathrm{M}(2)$, and the fluorescence spectra of AF obtained under excitation at $300 \mathrm{~nm}$ (3) and $240 \mathrm{~nm}$ (4). (b) Dependence of AF fluorescence intensity on the concentration of AF in the solution for $\lambda_{\text {ex. }}=300 \mathrm{~nm}(5)$ and $\lambda_{\text {ex. }}=240 \mathrm{~nm}$ (6).

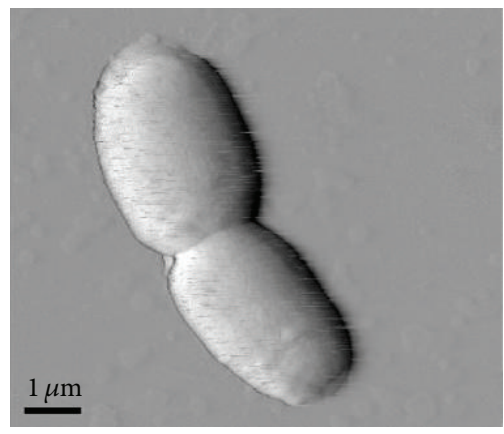

(a)

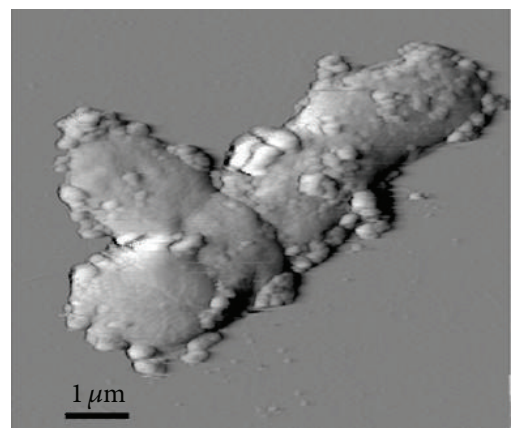

(b)

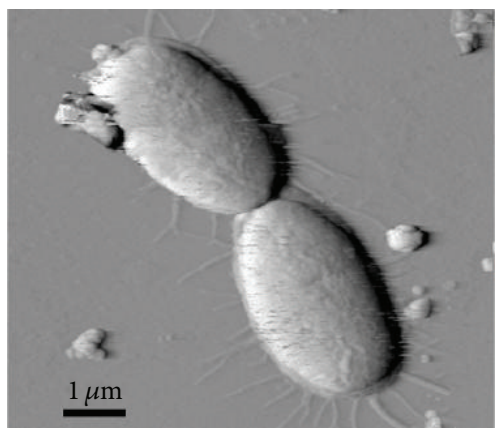

(c)

FIGURE 4: AFM images of E. coli K12 TG1 before (a) and after incubation with AF (b) and CF (c).

thus indicating that the remaining amount of this fullerene derivative is absorbed irreversibly. It can be estimated from these data that each $E$. coli cell absorbed irreversibly about $10^{5}$ molecules of AF.

The observed partially irreversible absorption of AF suggests the possibility of its penetration into the microbial cell, which was reported previously for some other fullerene derivatives [43]. The transmembrane AF diffusion could develop due to the concentration gradient and subsequently lead to the electrostatic binding of AF to the intracellular structures and molecules bearing negative charges (including DNA) [44].

This is our assumption at the present stage; further research will be performed to check this idea experimentally.

Similar desorption experiments were performed with CF. The obtained desorption values shown in Table 3 illustrate that four washing cycles removed $94.7 \pm 5.5 \%$ of CF applied in a very high initial concentration of $10 \mu \mathrm{M}$. Most of the fullerenes $(80.9 \pm 3.3 \%)$ were already washed out at the first cycle. This observation suggests that interactions of CF with the bacterial cells are very weak, which is in line with the experimental results described above.

3.6. Antibacterial Activity of Fullerene Derivatives against E. coli. The bactericidal effect of fullerene derivatives was evaluated by investigating the loss of the viability of $E$. coli K12 TG1 cells after a 60-minute incubation with different concentrations of AF and CF. Carboxylic fullerene derivative CF did not cause any bactericidal effect at concentrations of up to $400 \mu \mathrm{M}$. In contrast, the amino fullerene derivative showed notable bactericidal activity. The incubation of $E$. coli with AF led to the time- and concentration-dependent death of the bacterial cells (Table 4). The characteristic $\mathrm{LD}_{50}$ value of $79.1 \mu \mathrm{M}$ was calculated from the obtained data. Use of higher concentrations of this compound $(400 \mu \mathrm{M}$ and higher) resulted in the death of at least $99 \%$ of $E$. coli cells. These results suggest that AF might be considered as a novel and promising type of chemical bactericide. 
TABLE 3: Fullerene derivatives desorption from E. coli K12 TG1 cells.

\begin{tabular}{lcc}
\hline $\begin{array}{l}\text { Number of the consecutive } \\
\text { washing } \\
\text { (separation/redispersion) cycles }\end{array}$ & \multicolumn{2}{c}{$\begin{array}{c}\text { Fullerene derivative } \\
\text { desorption, } \%\end{array}$} \\
\hline 1 & AF & CF \\
2 & $16.5 \pm 1.0$ & $80.9 \pm 3.3$ \\
3 & $13.7 \pm 0.7$ & $6.7 \pm 0.5$ \\
4 & $8.3 \pm 0.5$ & $5.4 \pm 0.4$ \\
5 & $7.1 \pm 0.5$ & $1.7 \pm 0.1$ \\
6 & $4.9 \pm 0.4$ & 0 \\
7 & $4.2 \pm 0.3$ & 0 \\
8 & $3.7 \pm 0.2$ & 0 \\
9 & $2.7 \pm 0.2$ & 0 \\
10 & $2.2 \pm 0.1$ & 0 \\
\hline Total & $1.4 \pm 0.1$ & 0 \\
\hline
\end{tabular}

TABle 4: Percentage of the E. coli K12 TG1 cells that lost their vitality after 60 min of incubation with $\mathrm{AF}$ in the absence and in the presence of human erythrocytes.

\begin{tabular}{lcc}
\hline $\begin{array}{l}\text { Concentration of } \\
\text { AF, } \mu \mathrm{M}\end{array}$ & \multicolumn{2}{c}{ Bactericidal effect, \% } \\
& E. coli & $\begin{array}{c}\text { E. coli }+ \\
\text { erythrocytes }\end{array}$ \\
\hline 25 & $12.0 \pm 3.7$ & $1.8 \pm 4.4$ \\
50 & $31.9 \pm 3.1$ & $5.6 \pm 4.3$ \\
100 & $58.1 \pm 2.4$ & $6.0 \pm 4.3$ \\
200 & $77.6 \pm 1.4$ & $66.8 \pm 1.8$ \\
\hline
\end{tabular}

The selectivity of the antibacterial action of AF was investigated in a three-component test mixture comprising fullerene derivative, E. coli cells, and human erythrocytes. The concentrations of the cells in the test samples were adjusted to equalize the total areas $\left(0.02 \mathrm{~m}^{2} / \mathrm{mL}\right)$ of the $E$. coli and the erythrocyte cell surfaces. Indeed, the bactericidal activity of AF was essentially decreased in the presence of human erythrocytes in the test samples together with the E. coli cells (Table 4). The effect of the erythrocytes suppressing the antibacterial activity of AF was the most pronounced for concentrations $\leq 100 \mu \mathrm{M}$.

This observation is explained by nonspecific AF binding to the bacterial cells and erythrocytes. Such a concurrent pathway decreases the bactericidal activity of AF and increases $\mathrm{LD}_{50}$ value more than twofold for the system comprising both E. coli cells and human erythrocytes. The observed tendency of AF to bind to the erythrocytes hinders in vivo applications of this compound for fullerene-mediated therapy. Nevertheless, AF still can be considered as a promising chemical disinfectant for various types of surfaces.

\section{Conclusion}

Highly water-soluble derivatives of [60]fullerene bearing cationic (protonated amine, AF) or anionic (COO-, CF) functional groups appended to the fullerene cage have been investigated. It was shown that both fullerene derivatives form nanoclusters in aqueous solutions with hydrodynamic diameters of 2-200 nm (AF) and 70-100 nm (CF) as revealed by the DLS measurements.

The obtained experimental data implied that initial interactions of the fullerene derivatives and their nanoclusters with prokaryotic and eukaryotic cells are governed mainly by electrostatic Coulomb forces. Moreover, electrostatic interactions explain the appearance of the antibacterial activity of fullerene derivatives. Indeed, the cationic fullerene derivative AF (having zeta potential $\zeta=+41.5 \mathrm{mV}$ ) undergoes strong binding to the negatively charged $E$. coli cells $(\zeta=-50 \mathrm{mV})$ due to the attractive electrostatic interactions that result in the appreciable bactericidal activity of this compound. In contrast, the anionic fullerene derivative $\mathrm{CF}(\zeta=-52.2 \mathrm{mV})$ does not bind to the bacterial cell membranes because of the repulsive Coulomb interactions and subsequently shows no bactericidal effect. The binding of the amino fullerene (AF) clusters to the bacterial cells and also the absence of such binding in the case of CF were visualized by atomic force microscopy.

The fullerene derivative AF induced time- and concentration-dependent death of the bacterial E. coli cells characterized by an $\mathrm{LD}_{50}$ value of $79.1 \mu \mathrm{M}$. However, the antibacterial activity mechanism of [60]fullerene and fullerene derivatives is unclear and still debated [45]. Like Aquino et al. [46] we confirmed AF influence on the bacteria viability without cell membrane disruption. On the other hand, our results reaffirm AF intercalation into the cell wall that enables membrane stress [40], subsequent respiratory chain inhibition [47], and ROS-dependent toxicity [48].

The bactericidal activity of AF decreased significantly in the presence of human erythrocytes. Indeed, human erythrocytes also bear a negative charge $(\zeta=-13.5 \mathrm{mV})$, which facilitates their electrostatic interactions with the positively charged AF molecules (and/or nanoclusters). The efficient binding of AF (and, presumably, other positively charged fullerene derivatives) to both prokaryotic (E. coli) and eukaryotic (erythrocyte) cells hinders in vivo applications of such compounds for fullerene-mediated therapy. Nevertheless, AF can still be considered as a promising chemical disinfectant for various types of surfaces. In contrast, CF (and probably other anionic fullerene-based compounds) shows no ability to bind to the bacterial cells or erythrocytes and might have big potential for in vivo studies and, possibly, for some biomedicinal applications.

\section{Conflict of Interests}

The authors declare that there is no conflict of interests regarding the publication of this paper.

\section{Acknowledgments}

The authors acknowledge the financial support provided by the Russian Ministry of Science and Education (Contract 
no. P327), the Russian Foundation for Basic Research (1203-33031), the Russian President Science Foundation (MK6177.2013.3), and the Presidium of the Russian Academy of Sciences (Research Programs no. 8 "Development of methods for synthesis of new compounds and materials" and no. 24 "Fundamental research in the field of nanotechnology and nanomaterials").

\section{References}

[1] R. H. Hurt, M. Monthioux, and A. Kane, "Toxicology of carbon nanomaterials: status, trends, and perspectives on the special issue," Carbon, vol. 44, no. 6, pp. 1028-1033, 2006.

[2] S. Bosi, T. D. Ros, G. Spalluto, and M. Prato, "Fullerene derivatives: an attractive tool for biological applications," European Journal of Medicinal Chemistry, vol. 38, no. 11-12, pp. 913-923, 2003.

[3] R. Brayner, "The toxicological impact of nanoparticles," Nano Today, vol. 3, no. 1-2, pp. 48-55, 2008.

[4] M. S. Mauter and M. Elimelech, "Environmental applications of carbon-based nanomaterials," Environmental Science and Technology, vol. 42, no. 16, pp. 5843-5859, 2008.

[5] C.-W. Lam, J. T. James, R. McCluskey, S. Arepalli, and R. L. Hunter, "A review of carbon nanotube toxicity and assessment of potential occupational and environmental health risks," Critical Reviews in Toxicology, vol. 36, no. 3, pp. 189-217, 2006.

[6] J. Kolosnjaj-Tabi, H. Szwarc, and F. Moussa, "In vivo toxicity studies of pristine carbon nanotubes: a review," in The Delivery of Nanoparticles, A. A. Hashim, Ed., chapter 2, pp. 37-58, InTech, Vienna, Austeria, 2012.

[7] S. Nath, H. Pal, A. V. Sapre, and J. P. Mittal, "Solvatochromism. Aggregation and photochemical properties of fullerenes, $\mathrm{C}_{60}$ and $\mathrm{C}_{70}$, in solution," Journal of Photoscience, vol. 10, no. 1, $\mathrm{p}$. 105, 2003.

[8] F. Langa and J. -F. Nierengarten, Fullerenes: Principles and Applications, Nanoscience \& Nanotechnology, Royal Society of Chemistry, Cambridge, UK, 2007.

[9] P. A. Troshin, O. A. Troshina, R. N. Lyubovskaya, and V. F. Razumov, "Functional derivatives of fullerenes: synthesis and applications in the fields of organic electronics and biomedicine," Ivanovo: IvSU, 2010.

[10] S. C. Chueh, M. K. Lai, M. S. Lee, L. Y. Chiang, T. I. Ho, and S. C. Chen, "Decrease of free radical level in organ perfusate by a novel water-soluble carbon-sixty, hexa(sulfobutyl)fullerenes," Transplantation Proceedings, vol. 31, no. 5, pp. 1976-1977, 1999.

[11] R. Maeda-Mamiya, E. Noiri, H. Isobe et al., "In vivo gene delivery by cationic tetraamino fullerene," Proceedings of the National Academy of Sciences of the United States of America, vol. 107, no. 12, pp. 5339-5344, 2010.

[12] L. L. Dugan, D. M. Turetsky, C. Du et al., "Carboxyfullerenes as neuroprotective agents," Proceedings of the National Academy of Sciences of the United States of America, vol. 94, no. 17, pp. 94349439, 1997.

[13] Y. Tabata, Y. Murakami, and Y. Ikada, "Antitumor effect of poly(ethylene glycol)-modified fullerene," Fullerene Science and Technology, vol. 5, no. 5, pp. 989-1007, 1997.

[14] F. Kasermann and C. Kempf, "Photodynamic inactivation of enveloped viruses by buckminsterfullerene," Antiviral Research, vol. 34, no. 1, pp. 65-70, 1997.

[15] D. Y. Lyon, J. D. Fortner, C. M. Sayes, V. L. Colvin, and J. B. Hughes, "Bacterial cell association and antimicrobial activity of a $\mathrm{C}_{60}$ water suspension," Environmental Toxicology and Chemistry, vol. 24, no. 11, pp. 2757-2762, 2005.

[16] J. P. Kamat, T. P. A. Devasagayam, K. I. Priyadarsini, and H. Mohan, "Reactive oxygen species mediated membrane damage induced by fullerene derivatives and its possible biological implications," Toxicology, vol. 155, no. 1-3, pp. 55-61, 2000.

[17] T. Mashino, N. Usui, K. Okuda, T. Hirota, and M. Mochizuki, "Respiratory chain inhibition by fullerene derivatives: hydrogen peroxide production caused by fullerene derivatives and a respiratory chain system," Bioorganic and Medicinal Chemistry, vol. 11, no. 7, pp. 1433-1438, 2003.

[18] S. K. Sharma, L. Y. Chiang, and M. R. Hamblin, "Photodynamic therapy with fullerenes in vivo: reality or a dream?" Nanomedicine, vol. 6, no. 10, pp. 1813-1825, 2011.

[19] T. Mashino, D. Nishikawa, K. Takahashi et al., "Antibacterial and antiproliferative activity of cationic fullerene derivatives," Bioorganic and Medicinal Chemistry Letters, vol. 13, no. 24, pp. 4395-4397, 2003.

[20] N. Tsao, P. P. Kanakamma, T.-Y. Luh, C.-K. Chou, and H.Y. Lei, "Inhibition of Escherichia coli-induced meningitis by carboxyfullerence," Antimicrobial Agents and Chemotherapy, vol. 43, no. 9, pp. 2273-2277, 1999.

[21] A. A. Yurkova, E. A. Khakina, S. I. Troyanov et al., "Arbuzov chemistry with chlorofullerene $\mathrm{C}_{60} \mathrm{Cl}_{6}$ : a powerful method for selective synthesis of highly functionalized [60]fullerene derivatives," Chemical Communications, vol. 48, no. 71, pp. 8916-8918, 2012.

[22] E. A. Khakina, A. A. Yurkova, A. A. Peregudov et al., "Highly selective reactions of $\mathrm{C}_{60} \mathrm{Cl}_{6}$ with thiols for the synthesis of functionalized [60]fullerene derivatives," Chemical Communications, vol. 48, no. 57, pp. 7158-7160, 2012.

[23] A. B. Kornev, E. A. Khakina, S. I. Troyanov et al., "Facile preparation of amine and amino acid adducts of [60]fullerene using chlorofullerene $\mathrm{C}_{60} \mathrm{Cl}_{6}$ as a precursor," Chemical Communications, vol. 48, no. 44, pp. 5461-5463, 2012.

[24] A. B. Kornev, A. S. Peregudov, V. M. Martynenko, J. Balzarini, B. Hoorelbeke, and P. A. Troshin, "Synthesis and antiviral activity of highly water-soluble polycarboxylic derivatives of [70]fullerene," Chemical Communications, vol. 47, no. 29, pp. 8298-8300, 2011.

[25] O. A. Troshina, P. A. Troshin, A. S. Peregudov, J. Kozlovskiy, and R. N. Balzarini, "Photoaddition of N-substituted piperazines to $\mathrm{C}_{60}$ : an efficient approach to the synthesis of water-soluble fullerene derivatives," Chemistry, vol. 12, no. 21, pp. 5569-5577, 2006.

[26] O. A. Troshina, P. A. Troshin, A. S. Peregudov, V. I. Kozlovskiy, J. Balzarini, and R. N. Lyubovskaya, "Chlorofullerene $\mathrm{C}_{60} \mathrm{Cl}_{6}$ : a precursor for straightforward preparation of highly watersoluble polycarboxylic fullerene derivatives active against HIV," Organic and Biomolecular Chemistry, vol. 5, no. 17, pp. 27832791, 2007.

[27] S. Kang, M. Herzberg, D. F. Rodrigues, and M. Elimelech, "Antibacterial effects of carbon nanotubes: size does matter!," Langmuir, vol. 24, no. 13, pp. 6409-6413, 2008.

[28] D. Bouchard, X. Ma, and C. Isaacson, "Colloidal properties of aqueous fullerenes: isoelectric points and aggregation kinetics of $\mathrm{C}_{60}$ and $\mathrm{C}_{60}$ derivatives," Environmental Science \& Technology, vol. 43, no. 17, pp. 6597-6603, 2009.

[29] G. Wang, G. Zhao, and L. Yan, "Relationship between toxicity and molecular volume of dioxins, organic phosphorous compounds and n-alkanols," Chinese Science Bulletin, vol. 49, no. 14, pp. 1437-1441, 2004. 
[30] S. S. Gayathri and A. Patnaik, "Aggregation of a $\mathrm{C}_{60}$-didodecyloxybenzene dyad: structure, dynamics, and mechanism of vesicle growth," Langmuir, vol. 23, no. 9, pp. 4800-4808, 2007.

[31] Y. Kanbur and Z. Küçükyavuz, "Synthesis and characterization of surface modified fullerene," Fullerenes, Nanotubes and Carbon Nanostructures, vol. 20, no. 2, pp. 119-126.

[32] X. Ma and D. Bouchard, "Formation of aqueous suspensions of fullerenes," Environmental Science \& Technology, vol. 43, no. 2, pp. 330-336, 2009.

[33] E. Yifeng, L. Bai, L. Fan, M. Han, X. Zhang, and S. Yang, "Electrochemically generated fluorescent fullerene[60] nanoparticles as a new and viable bioimaging platform," Journal of Materials Chemistry, vol. 21, pp. 819-823, 2011.

[34] Y. Matsuo, K. Tahara, K. Morita, K. Matsuo, and E. Nakamura, "Regioselective eightfold and tenfold additions of a pyridinemodified organocopper reagent to [60]fullerene," Angewandte Chemie, vol. 46, no. 16, pp. 2844-2847, 2007.

[35] D. Y. Lyon and P. J. Alvarez, "Fullerene water suspension $\left(\mathrm{nC}_{60}\right)$ exerts antibacterial effects via ROS-independent protein oxidation," Environmental Science \& Technology, vol. 42, no. 21, pp. 8127-8132, 2008.

[36] M. HuiLi and X. J. Liang, "Fullerenes as unique nanopharmaceuticals for disease treatment," Science China Chemistry, vol. 53, no. 11, pp. 2233-2240, 2010.

[37] S. Liu, A. K. Ng, R. Xu et al., "Antibacterial action of dispersed single-walled carbon nanotubes on Escherichia coli and Bacillus subtilis investigated by atomic force microscopy," Nanoscale, vol. 2, no. 12, pp. 2744-2750, 2010.

[38] H. Schwegmann, A. J. Feitza, and F. H. Frimmela, "Influence of the zeta potential on the sorption and toxicity of iron oxide nanoparticles on S. cerevisiae and E. coli," Journal of Colloid and Interface Science, vol. 347, no. 1, pp. 43-48, 2010.

[39] N. Guzelsu, C. Wienstien, and S. P. Kotha, "A new streaming potential chamber for zeta potential measurements of particulates," Review of Scientific Instruments, vol. 81, no. 1, Article ID 015106, 2010.

[40] Y. J. Tang, J. M. Ashcroft, D. Chen et al., "Charge-associated effects of fullerene derivatives on microbial structural integrity and central metabolism," Nano Letters, vol. 7, no. 3, pp. 754-760, 2007.

[41] H. J. Johnston, G. R. Hutchison, F. M. Christensen, K. Aschberger, and V. Stone, "The biological mechanisms and physicochemical characteristics responsible for driving fullerene toxicity," Toxicological Sciences, vol. 114, no. 2, pp. 162-182, 2009.

[42] F. Rancan, S. Rosan, F. Boehm et al., "Cytotoxicity and photocytotoxicity of a dendritic $\mathrm{C}_{60}$ mono-adduct and a malonic acid $\mathrm{C}_{60}$ tris-adduct on Jurkat cells," Journal of Photochemistry and Photobiology B, vol. 67, no. 3, pp. 157-162, 2002.

[43] J. Wong-Ekkabut, S. Baoukina, W. Triampo, I.-M. Tang, D. P. Tieleman, and L. Monticelli, "Computer simulation study of fullerene translocation through lipid membranes," Nature Nanotechnology, vol. 3, no. 6, pp. 363-368, 2008.

[44] I. Nakanishi, S. Fukuzumi, T. Konishi et al., "Fullerenes for the new millennium," in Proceedings of the International Symposium on Fullerenes, Nanotubes, and Carbon Nanoclusters, P. V. Kamat, D. M. Guldi, and K. M. Kadish, Eds., vol. 11, The Electrochemical Society, Pennington, NJ, USA, 2001.

[45] M. Carini, L. Djordjevic, and T. D. Ros, "Fullerenes in biology and medicine," in Handbook of Carbon Nano Materials, vol. 3, pp. 1-48, World Scientific Publishing, 2012.
[46] A. Aquino, J. Chan, K. Giolma, and M. Loh, "The effect of a fullerene water suspension on the growth, cell viability, and membrane integrity of Escherichia coli B23," Journal of Eexperimental Microbiology \& Immunology, vol. 14, pp. 13-20, 2010.

[47] T. Mashino, K. Okuda, T. Hirota, M. Hirobe, T. Nagano, and M. Mochizuki, "Inhibition of $E$. coli growth by fullerene derivatives and inhibition mechanism," Bioorganic and Medicinal Chemistry Letters, vol. 9, no. 20, pp. 2959-2962, 1999.

[48] G. P. Tegos, T. N. Demidova, D. Arcila-Lopez et al., "Cationic fullerenes are effective and selective antimicrobial photosensitizers," Chemistry and Biology, vol. 12, no. 10, pp. 1127-1135, 2005. 

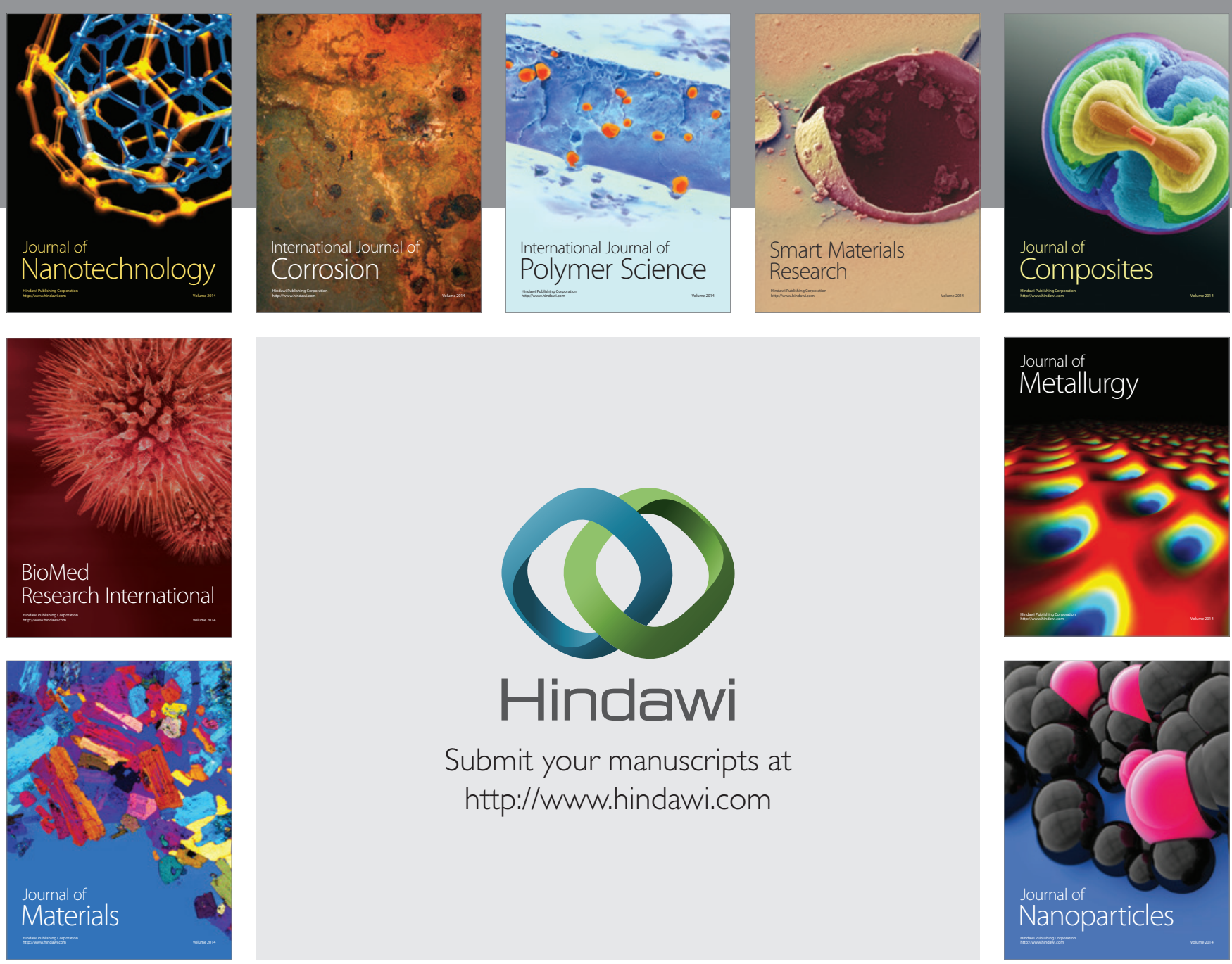

Submit your manuscripts at http://www.hindawi.com
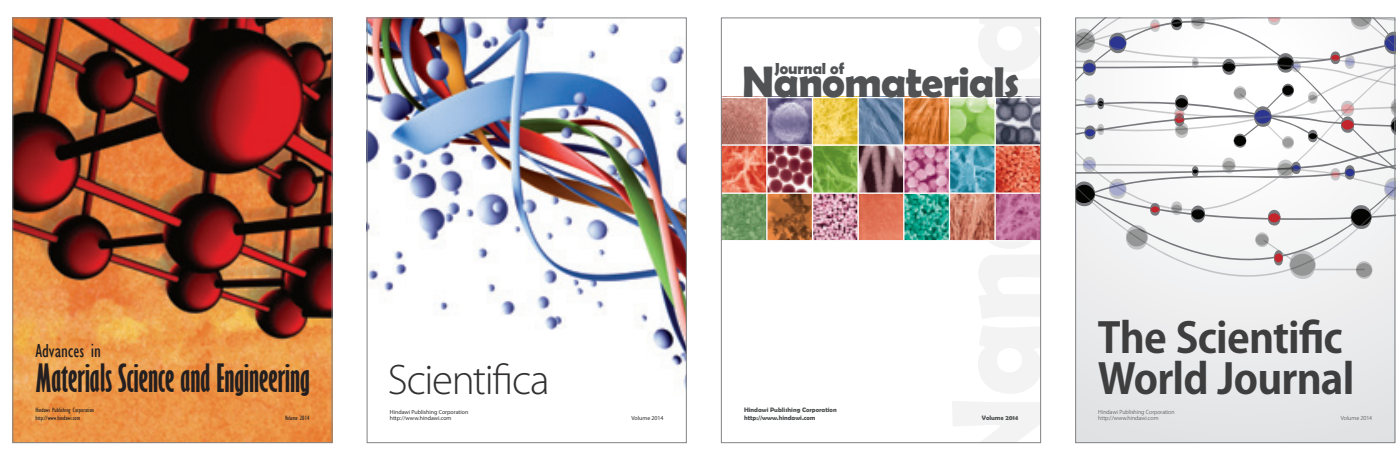

\section{The Scientific World Journal}
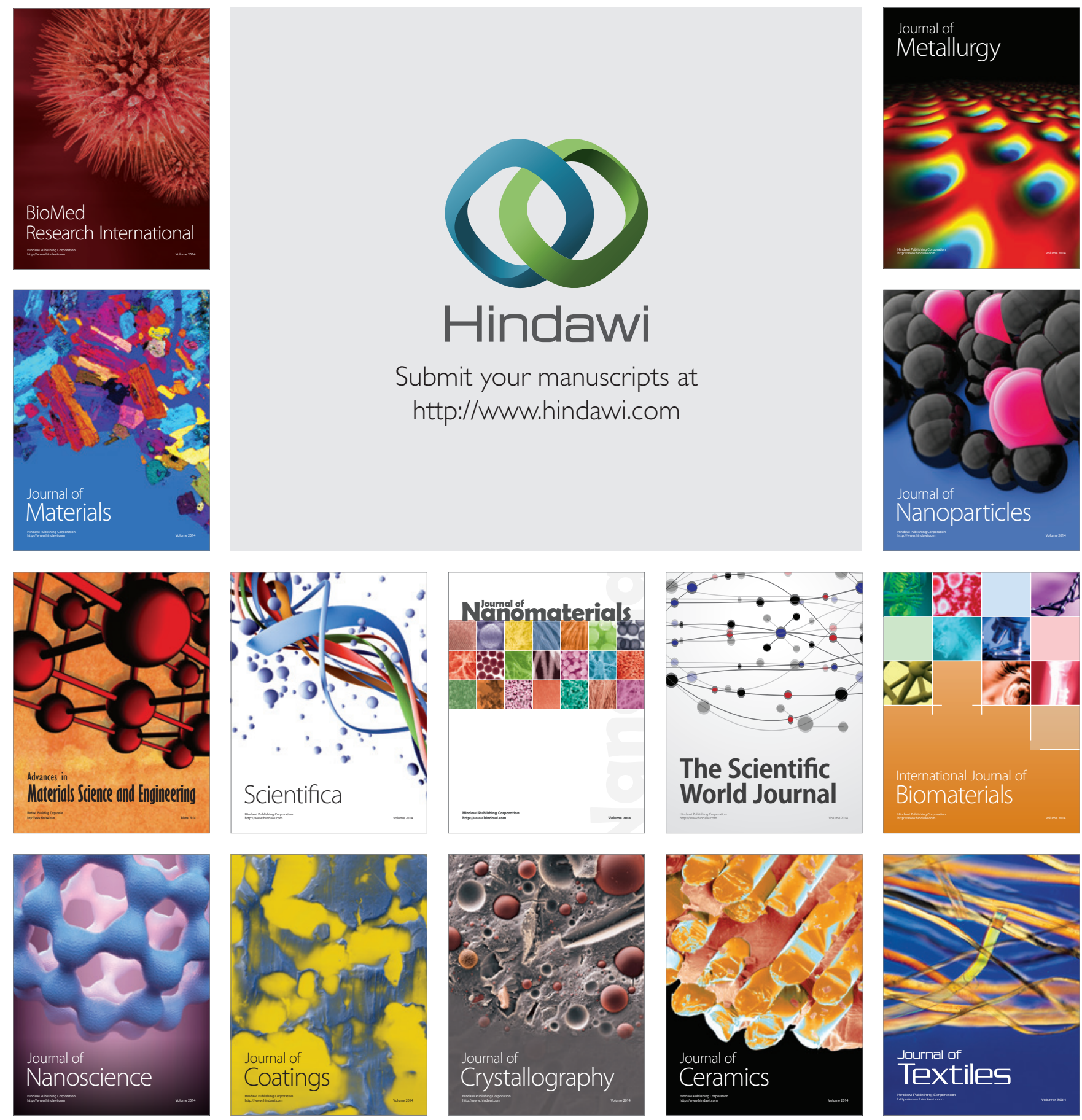